\title{
A subjective and objective fuzzy-based analytical hierarchy process model for prioritization of lean product development practices
}

\author{
Daniel O. Aikhuele ${ }^{a^{*}}$ and Faiz M. Turan ${ }^{a}$
}

${ }^{a}$ Faculty of Manufacturing Engineering, Universiti Malaysia Pahang, Pekan, 26600, Pahang-Malaysia

\begin{tabular}{l}
\hline C H R O N I C L E \\
\hline Article history: \\
Received: October 1, 2016 \\
Received in revised format: No- \\
vember 16, 2016 \\
Accepted: March 16, 2017 \\
Available online: \\
March 16, 2017 \\
\hline Keywords: \\
Lean product development \\
Fuzzy-based AHP model \\
Fuzzy pairwise comparison ma- \\
trix \\
Arithmetic mean equation \\
Evaluation matrix
\end{tabular}
\section{A B S T R A C T}

\begin{abstract}
In this paper, a subjective and objective fuzzy-based Analytical Hierarchy Process (AHP) model is proposed. The model which is based on a newly defined evaluation matrix replaces the fuzzy comparison matrix (FCM) in the traditional fuzzy AHP model, which has been found ineffective and time-consuming when criteria/alternatives are increased. The main advantage of the new model is that it is straightforward and completely eliminates the repetitive adjustment of data that is common with the FCM in traditional AHP model. The model reduces the complete dependency on human judgment in prioritization assessment since the weights values are solved automatically using the evaluation matrix and the modified priority weight formula in the proposed model. By virtue of a numerical case study, the model is successfully applied in the determination of the implementation priorities of lean practices for a product development environment and compared with similar computational methods in the literature.
\end{abstract}

\section{Introduction}

Multiple criteria decision making (MCDM) is a sub-discipline of operation research, and it is concerned with problems of prioritizing, screening, ranking or selecting of multiple conflicting criteria/alternative(s) from among a finite set of candidates (Braglial et al., 2003). Many of our everyday decisionmaking problems involve the consideration of multiple criteria or attributes. Also corporate decisionmaking, which often involves a complex decision process in which fuzzy conditions and requirements have to be considered and accounted for, rarely involves a single criterion (Leonardi, 2016; Roszkowska, 2013). A typical MCDM problem can be represented using the following notations (Hwang \& Yoon 1981);

$X=\left\{X_{1}, X_{2}, \ldots, X_{m}\right\}:$ a discrete or continuous set of $m$ possible alternatives.

$R=\left\{R_{1}, R_{2}, \ldots, R_{n}\right\}:$ a set of $n$ attributes that are objective and additively independent.

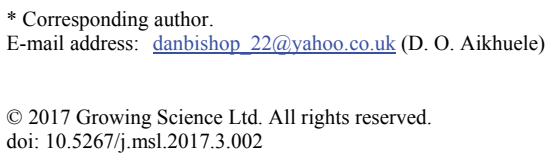


$w=\left(w_{1}, w_{2}, \ldots, w_{n}\right)^{T}:$ the vector with attribute weights where $w=\sum_{\mathrm{j}=1}^{\mathrm{n}} w_{j}=1, w_{j} \geqslant 0 \forall j$.

while;

$B=\left[b_{i j}\right]_{m x n}$ : is the decision matrix where $b_{i j}$ is the consequence with a numerical value for alternative $i$ with respect to attribute $j, i=1, \ldots, m, j=1, \ldots, n$.

Every element $\left(b_{i j}\right)$ in the decision matrix $B$ is expected to be an objective value that is between the range 0 and 1 . This is mainly to ensure all the attributes in matrix to have the same range of measurement. To achieve this, elements in the matrix are normalized into a corresponding element in matrix $D=\left[d_{i j}\right]_{m x n}$ using the following formulas;

$$
\begin{aligned}
& d_{i j}=\frac{b_{i j}-b_{j}^{\min }}{b_{j}{ }^{\text {max }}-b_{j}{ }^{\min }}, i=1, \ldots, m, j=1, \ldots, n, \text { for benefit attributes } \\
& d_{i j}=\frac{b_{j}^{\text {max }}-b_{i j}}{b_{j}{ }^{\text {max }}-b_{j}{ }^{\text {max }}}, i=1, \ldots, m, j=1, \ldots, n, \text { for cost attributes } \\
& b_{j}^{\text {max }}=\max \left\{b_{1 j}, b_{2 j}, \ldots, b_{m j}\right\} \\
& b_{j}^{\text {min }}=\min \left\{b_{1 j}, b_{2 j}, \ldots, b_{m j}\right\}
\end{aligned}
$$

The Decision Maker(s) (DM) will then choose the most preferred alternative $\mathbf{X}^{*}$ from the set $X, \mathbf{X}^{*} \in X$.

In applying MCDM methods, several computational steps are followed before the right or optimum criteria/alternative is determined. The accuracy of the multiple criteria analysis results is said to be largely influenced by the values of the criteria weights applied (GINEVIČIUS, 2011). The assessment and obtaining of the relative importance weights of the different criteria hence remains one of the most important and crucial tasks in the implementation of MCDM method for the selection, prioritization, and screening of alternatives. Although, the criteria weights don't have clear economic significance, however, they are capable of influencing the results as well as the decision made using the MCDM analysis methods (Til et al., 2014). Several different methods and approach have been proposed and applied in literature for the determination of criteria weights, details of some of the methods have been briefly discussed in section 2 .

In this paper, however, we are proposing a subjective and objective fuzzy-based Analytical Hierarchy Process (AHP) model by extending the Fuzzy Matrix in the AHP model in (Kong \& Liu, 2005) and the priority weight formula in (Nurnadiah \& Lazim, 2012). To address the fuzzy comparison matrix (FCM) which has been found ineffective and time-consuming when criteria/alternatives are increased (Kong \& Liu, 2005) in traditional AHP model and to account for the experience and expertise of the assessors (experts) which are not considered in the traditional AHP model. Where, this extension is hoped to bring about a balance in the collected data and to eliminate experts bias, which normally results in data inconsistency and the need for data adjustments and consistency check that common with traditional fuzzy AHP models (Aly \& Vrana, 2008).

AHP model is a structured technique used for organizing and analyzing complex decisions, based on mathematics and psychology (Christopher \& John, 2014). Its theory is based on measurements which rely on pairwise comparisons of experts judgments to derive priority scales and then optimum decision. The main purpose of proposing this extension is to provide a criteria weight assessment method that is both subjective and objective and able to address data inconsistency, data adjustments in the traditional fuzzy AHP that have been found to be time-consuming and to account for the experience and expertise of the assessors (experts) which are not considered in traditional AHP model.

The rest of the paper is organized as follows; in Section 2, criteria weight assessment methods are briefly reviewed. Section 3 presents, a review of the traditional fuzzy AHP model and the extension that have introduced. Application of the proposed subjective and objective fuzzy-based AHP model is 
presented in Section 4 and finally, some concluding remarks and future direction are given in Section 5.

\section{Criteria weight assessment methods}

The determination and aggregation of the criteria weights, which are used for comparing alternatives, remains one of the most difficult tasks in the implementation of multiple criteria decision analysis (MCDA) methods (Kao, 2010). Several different methods and approaches have been proposed and applied in literature and these methods and approaches can be classified as either subjective, objective or both depending on the information provided. Prominent among the subjective approach includes; the Analytical Hierarchy Process (AHP) and Analytical Network Process (ANP) which are both based on the pairwise comparison, however, their drawbacks have been detailed in (Oguztimur, 2011), other methods includes Delphi method (Ishikawa et al., 1993), simple additive weighting method (Hwang \& Yoon, 1981) etc. The application of subjective approaches for the determination of criteria weights is usually based on preference information of the criteria, and on the fact that all the DMs clearly understand the interpretation of the criteria weights. However, this is rarely the case in most real case studies.

In the objective approach, the criteria weights are determined through mathematical calculation using objective information in a decision matrix. Among the prominent objective weight approach includes; Standard Deviation weight method (Baruah \& K, 1999), Shannon's entropy weight method (Chaghooshi, et al., 2012) which are some referred to as a subjective and objective method, and finally the objective and subjective weight method (Ma, Fan, \& Huang, 1999). In this study, we aimed to presents a reliable, easy and straightforward approach for determining criteria weight by using both subjective and objective factors in forming a fuzzy-based AHP model for solving selection, prioritization, and decision-making problems.

\section{Fuzzy Analytical Hierarchy Process (Fuzzy-AHP)}

Fuzzy AHP is a systematic and excellent multi-criteria decision-making tool for solving both quantitative and qualitative problems in which its information are vague, inconsistent and sometimes fuzzy. The fuzzy AHP model is unique for its ability to deal with such fuzziness and vagueness of linguistic judgments by establishing an effective prioritization. The fuzzy AHP method was borne out of the inability of the traditional AHP to deal with imprecision and subjectiveness in the pair-wise comparison process (Aikhuele et al., 2014; Wang \& Chin, 2011).

There are different approaches to solving the fuzzy AHP-based model. The main characteristics of these approaches, their advantages, and disadvantages with their several points of view have been reviewed by Kahraman et al. (2004). However, among the approaches that have found prominent application in the literature include Chang's extent analysis and the row geometric mean method. The main philosophy behind this theory and approaches are expressed and supported with real case applications in (Chang, 1996; Parmar \& Bhoi, 2015), here the triangular fuzzy numbers are used for the fuzzy AHP pairwise comparison scale, while the extent analysis method is used for calculating the synthetic extent values of the pairwise comparisons. Other approaches not mention in (Kahraman et al., 2004) includes, the Saaty's evaluation approach which uses the principal eigenvector of pairwise comparison matrix which is derived from the scaling ratio used for finding comparative weight among the criteria (Kong $\&$ Liu, 2005; Saaty, 2008), and the fuzzy AHP row arithmetic mean method for fuzzy weight evaluation which uses fuzzified and defuzzified approach to obtain the priority weight.

Although the fuzzy AHP row geometric mean method, fuzzy AHP row arithmetic mean method and Chang's extent analysis appear relatively easy to compute as compared to other fuzzy AHP approaches 
that have been proposed. However, they often become limited when the number of criteria or alternatives in the hierarchy increases, meaning more and more comparisons are then required between the criteria or alternatives and this normally cause confusion even to AHP experts due to the excess of questions arising from criteria or alternatives. In most cases, this excess of questions may reduce the efficiency of the model altogether as well as the introduction of erroneous data. So to correct this drawback, consistency check are normally performed for the pair-wise comparison matrix and when these inconsistencies persist, the elements in the matrixes are adjusted and consistency check carries out again, and again until the matrix is consistent.

This consistency check approach, however, has been found to be time-consuming (Ramik, 2009). Hence, in the effort to solve the time related issue, some few researchers has extended and modify the original Saaty's comparison matrix to suit their particular problem and research aim, among them we can mention Ramik (2009), who presented a pair-wise comparison matrix (PCM) with a triangular fuzzy element which uses logarithmic least squares for eliciting associated weights. Turan (2013) presented a pair-wise comparison matrix (PCM) for computing priorities criteria elements in the evaluation of product design at the early stage of product development. Although each of the comparison matrix described in these literature offers their own contributions to reducing the adjustment time, however, none considered, the need to remove such inconsistency in the matrix and data provide by the engaged experts from the start, which actually is the main reason for the repeated consistency check and adjustment. This is important, most especially for AHP evaluation procedure that doesn't use the Saaty's eigenvalue method (EVM), in which consistency checks are not possible. The proposed extension to the fuzzy AHP model in this study is aimed at solving this issue. The extension has been described in details in section 3.1; meanwhile, the stepwise procedure for computing the traditional fuzzy AHP is given below.

Step 1. Determine the degree of the importance of each criterion

Step 2. Construct the hierarchical framework

Step 3. Design the fuzzy comparison matrix

Step 4. Calculate the arithmetic mean weight for each of the criteria and alternatives

Step 5. Finally, calculate the fuzzy priority weight.

\subsection{Subjective and objective fuzzy AHP model}

Considering the drawback in the fuzzy AHP model as stated above, this study intends to address this issue by extending and improving the evaluation matrix and the priority weight formula in the fuzzy AHP model originally proposed in (Kong \& Liu, 2005; Ramik, 2009; Turan, 2013) by employing both a subjective and objective factors/approach for implementing the fuzzy AHP model. In replacing the FCM/PCM in the traditional AHP model with the new evaluation matrix, first a new expert's weighing scale is introduced which is used in balancing and reducing bias in the assessment values given by the experts and a new criteria rating scale (i.e. a Membership rating scale) in place of the traditional Saaty scale and pairwise equation (see equation 5) which often requires a lot of adjustment and too many comparisons when the criteria increases. Details of the full extension are given below.

$$
A=\left[\begin{array}{cccc}
\frac{W_{1}}{W_{1}} & \frac{W_{1}}{W_{2}} & \cdots & \frac{W_{1}}{W_{n}} \\
\frac{W_{2}}{W_{1}} & \frac{W_{2}}{W_{2}} & \vdots & \frac{W_{2}}{W_{n}} \\
\vdots & \vdots & & \vdots \\
\vdots & \vdots & \vdots & \vdots \\
\frac{W_{n}}{W_{1}} & \frac{W_{n}}{W_{2}} & \cdots & \frac{W_{n}}{W_{n}}
\end{array}\right]=\left[\begin{array}{cccc}
a_{11} & a_{12} & \cdots & a_{1 n} \\
a_{21} & a_{22} & \cdots & a_{2 n} \\
\vdots & \vdots & \cdots & \vdots \\
\vdots & \vdots & \cdots & \vdots \\
a_{n 1} & a_{n 2} & \cdots & a_{n n}
\end{array}\right]
$$




\subsubsection{Membership rating scale}

The new membership rating scale is based on the fuzzy set theory and is an extension of the fuzzy Likert scale in ( $\mathrm{Li}, 2010)$ and is designed in such a way that it allows the assessors (experts) to choose from a range of values, as such allowing them to have or express partial agreement to a response, where the partial agreement between any two linguistic terms takes the form of a decimal number (membership scale), while the agreement level of responses in the scale is approximated to a decimal place. The membership rating scale is designed to address problems resulting from information distortion and information lost due to the closed-form scaling and the ordinal nature that exist in the traditional Likert scale as well as in the Saaty's scale. The new scale is shown in Table 1.

\section{Table 1}

Membership rating scale

\begin{tabular}{cc}
\hline Numerical rating & Description \\
\hline 0.1 & Undecided \\
\hline 0.15 (or between 0.1 and 0.2$)$ & Very Unsatisfactory \\
0.25 (or between 0.2 and 0.3$)$ & Unsatisfactory \\
0.35 (or between 0.3 and 0.4$)$ & Developing \\
0.45 (or between 0.4 and 0.5$)$ & Proficient \\
0.55 (or between 0.5 and 0.6$)$ & Exemplary \\
\hline
\end{tabular}

\subsubsection{Experts weighing scale}

In order to control spurious influence of the expert's bias that may arise in the course of rating the alternatives/criteria, the experts are assigned a weight $\left(W_{j}\right)$ according to the level of their expertise and experience. This is important, considering the differences in level of experience and expertise of the experts as it relates to the lean practice in the product development. The expert weighting scale is shown in Table 2.

Table 2

Experts weighing scale

\begin{tabular}{cc}
\hline Experts and their positions & Experts weight \\
\hline Experts 1 & 0.25 \\
Experts 2 & 0.35 \\
Experts 3 & 0.40 \\
\hline
\end{tabular}

\subsubsection{The Proposed Evaluation Matrix}

The new evaluation matrix has been introduced as a replacement for the FCM in the traditional AHP model. The new matrix which is an extension of evaluation matrix in the fuzzy AHP model in (Kong \& Liu, 2005; Ramik, 2009; Turan, 2013) is implemented using both subjective and objective approach. The subjective aspect of the evaluation is the part where the data are collected from experts in the field, while the objective part is the final weight calculation using the evaluation matrix and the priority weight formula. The subjective aspect is designed in such a way that inconsistency, distortion, and loss of information in the data provide by the experts are taken care of from the start even before the analysis, using the membership scale and experts weighing scale. The data and information given by the experts are aggregated using the Ordered Weighted Geometric (OWG) operator originally proposed by Chiclana et al. (2002). The OWG operator is defined as;

$$
O W G\left(a_{1}, a_{2}, \ldots, a_{n}\right)=\prod_{i=1}^{n} b_{i}{ }^{w_{i}}=D_{i} W,
$$


where $\left(a_{1}, a_{2}, \ldots, a_{n}\right)$ is a collection of non-negative real numbers, $b_{i}$ is the $i$ th largest element of the collection of $\left(a_{1}, a_{2}, \ldots, a_{n}\right)$, while $w_{i}$ is the weight vector of the experts.

The aggregated values from the computation of the OWG operation $\left(D_{i} W\right)$ are inputted into the evaluation matrix and then to the modified priority weight formula in fuzzy AHP model for determining the final weight of the alternatives. The new evaluation matrix is shown in Eqs. (7-8) below. The matrix which represents the objective aspect of the model can be said different from the traditional and modified FCM/PCM in (Kong \& Liu, 2005; Ramik, 2009; Turan, 2013) for the following reasons;

(1) The experience and expertise of the assessors (experts) are considered in the analysis; the collected data are balance, with no bias which could result in a reduction in data inconsistency which is one of the main reasons for the continuous adjustments and the consistency check in the traditional fuzzy AHP.

(2) The data collected are based on membership scale, meaning the experts are allowed to have a partial agreement to a response or question and they can choose the answers from a range of data (interval),

(3) The diagonal of the matrix is 0.5 unlike the traditional Satty's PCM that is 1 , although this value has no direct effect on the computation,

(4) The framework of the new fuzzy-based AHP model is based on both subjective and objective factors,

(5) The evaluation matrix in fuzzy AHP model is flexible, easy and the computation process is straightforward as compared to the other reviewed methods and finally.

(6) The objective aspect of determining the weight automatically using the mathematical model makes the result more reliable.

(7) It uses the OWG operator for aggregating the experts' opinion and judgments.

$$
\begin{gathered}
M M=\left[\begin{array}{cccc}
\frac{D_{1} W}{D_{1} W+D_{1} W} & \frac{D_{1} W}{D_{1} W+D_{2} W} & \frac{D_{1} W}{D_{1} W+D_{3} W} & \frac{D_{1} W}{D_{1} W+D_{n} W} \\
\frac{D_{2} W}{D_{2} W+D_{1} W} & \frac{D_{2} W}{D_{2} W+D_{2} W} & \frac{D_{2} W}{D_{2} W+D_{3} W} & \frac{D_{2} W_{2}}{D_{2} W+D_{n} W} \\
\vdots & \vdots & \vdots & \vdots \\
\vdots & \vdots & \vdots & \vdots \\
\frac{D_{n} W}{D_{n} W+D_{1} W} & \frac{D_{n} W}{D_{n} W+D_{2} W} & \frac{D_{n} W}{D_{n} W+D_{3} W} & \frac{D_{n} W}{D_{n} W+D_{n} W}
\end{array}\right]=\left[\begin{array}{cccc}
a_{11} & a_{12} & \cdots & a_{1 n} \\
a_{21} & a_{22} & \cdots & a_{2 n} \\
\vdots & \vdots & \cdots & \vdots \\
\vdots & \vdots & \cdots & \vdots \\
a_{n 1} & a_{n 2} & \cdots & a_{n n}
\end{array}\right] \\
M M=\left[\begin{array}{ccccc}
0.5 & \frac{D_{1} W}{D_{1} W+D_{2} W} & \frac{D_{1} W}{D_{1} W+D_{3} W} & \frac{D_{1} W}{D_{1} W+D_{n} W} \\
\frac{D_{2} W}{D_{2} W+D_{1} W} & 0.5 & \frac{D_{2} W}{D_{2} W+D_{3} W} & \frac{D_{2} W_{2}}{D_{2} W+D_{n} W} \\
\vdots & \vdots & 0.5 & \vdots \\
\vdots & \vdots & \vdots & \vdots \\
\frac{D_{n} W}{D_{n} W+D_{1} W} & \frac{D_{n} W}{D_{n} W+D_{2} W} & \frac{D_{n} W}{D_{n} W+D_{3} W} & 0.5
\end{array}\right]=\left[\begin{array}{cccc}
a_{11} & a_{12} & \cdots & a_{1 n} \\
a_{21} & a_{22} & \cdots & a_{2 n} \\
\vdots & \vdots & \cdots & \vdots \\
\vdots & \vdots & \cdots & \vdots \\
a_{n 1} & a_{n 2} & \cdots & a_{n n}
\end{array}\right]
\end{gathered}
$$

The new MM is only valid when the following conditions are mean;

$$
a_{i i}=0.5, a_{i j}+a_{j i} \leq 1, \quad \frac{1}{a_{i j}}-1=\left(\frac{1}{a_{i K}}-1\right) \times\left(\frac{1}{a_{K i}}-1\right)
$$

where $a_{i i}$ is the degree of importance of a particular criterion.

The membership rating scale is valid only if the values in computation fall within the range $[0,1]$. According to Stirn and Grošelj (2010). 'If the comparison matrices of all Experts are of acceptable consistency, then the aggregated comparison matrix (weighted geometric mean and arithmetic mean) is also of acceptable consistency'. 
Proof: We can prove the equation $7 \& 8$ by mathematical induction and the similar proof method can be referred to (Avicnnasis, 2011; Prasolov, 1994).

\subsubsection{Modified priority weight}

In calculating the priority weight, the arithmetic row means method has been utilized, where this is due to the small number of Experts (E) (less than 50) engaged in the study (Wu et al., 1998). The arithmetic mean matrix for the criteria (lean practices) weight evaluation is based on the integrated row arithmetic mean average weight method originally proposed by Nurnadiah \& Lazim, (2012), where it have been extended by incorporating the evaluation matrix into the equation (i.e. summing the values in each row of the evaluation matrix). The new row arithmetic mean equation is given in Eq. (10) below, where $E$ represents the number of Experts engaged in the assessment.

$$
W_{C_{i}}=\frac{1}{E}\left[\sum_{j=1}^{E} \frac{D_{j} W}{D_{j} W+D_{j} W}\right]
$$

Finally, the fuzzy priority weight for the criteria or alternatives is calculated using Eq. (10).

$$
W_{F_{i}}=\left[\frac{W_{C_{i}}}{\Sigma W_{C_{i}}}\right]
$$

\subsection{Algorithm of the Proposed subjective and objective fuzzy-based AHP model}

Step 1. Determine the degree of the importance of each criterion from each of the experts using the Membership rating scale and then aggregate the information with their different weight values using the OWG operator.

Step 2. Construct the hierarchical framework

Step 3. Input the aggregated experts comprehensive values in the evaluation matrix

Step 4. Calculate the arithmetic mean weight for each of the criterion using values from the evaluation matrix

Step 5. Finally, calculate the fuzzy priority weight.

\section{Case Application of the Proposed Model}

In this section, a numerical application of the proposed subjective and objective fuzzy AHP model is presented for determining and prioritizing lean practices in a product development environment with the view to maximizing product value, product quality as well as minimize the development time and cost. The hierarchical framework for the evaluation has been presented in figure 1 .

In collecting empirical information and data for determining the implementation priorities of the lean practices, first an initial assessment was done using data and information collected from academic experts, where the information was used in screening the lean practices to seven (7) as shown in Table 3, while for the final evaluation, the data were collected from a group of twelve (12) industrial experts in an automotive related company in Malaysia using the membership rating scale. The evaluating experts which comprise of Designer Engineers/Managers, Product Development Engineers/Managers, Sales Coordinators and Lean practitioner were drawn from three (3) units in the company (i.e. Design Engineering Unit, R\&D unit, and Sales/OEM customers unit) and from the management team. The justification for using the small number of expert's opinions in this study is based on the fact that a "good 
research comes from asking the right question of the right person". Hence, the study has concentrated on getting information and opinions from experts and practitioners in the field.

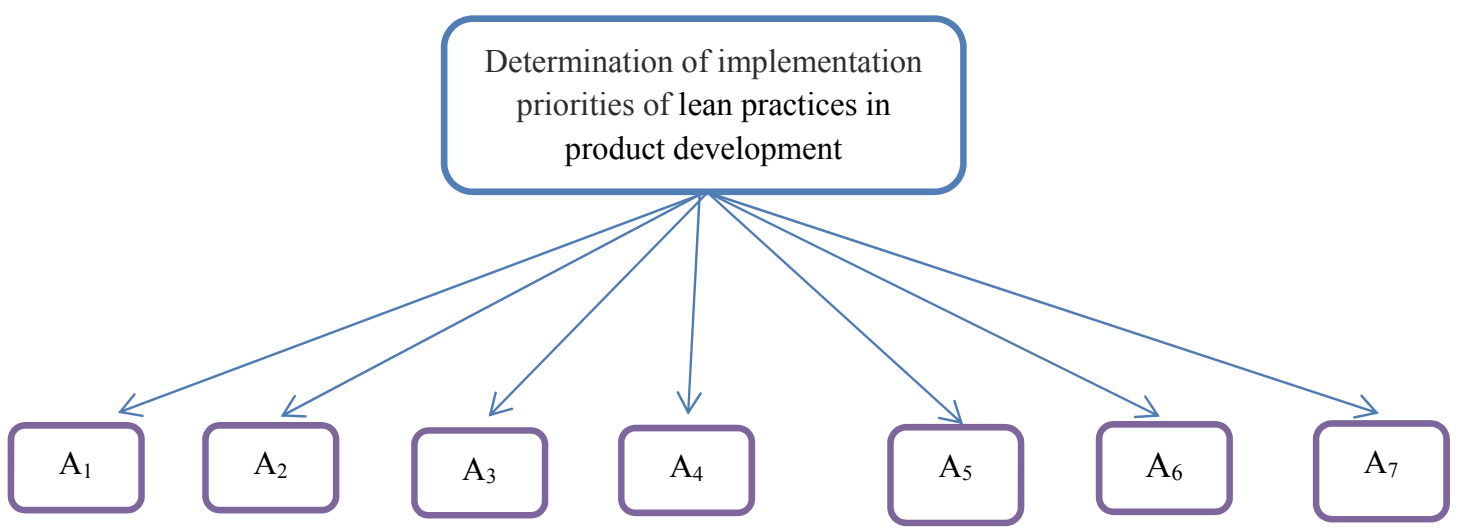

Fig. 1. Hierarchy model of lean implementation for the extended FAHP study

Table 3

Lean practices in Product development and their literature support

\begin{tabular}{lcl}
\hline & Lean product development practices & Literature support \\
\hline (1) & Set-based concurrent engineering & (Aikhuele \& Turan, 2016b; Al-ashaab, et al., 2013) \\
(2) & Strong project manager & (Al-ashaab et al., 2013; Al-Ashaab et al., 2015; Khan \& \\
(3) & Cross-functional teams & Al-Ashaab, 2013). \\
(4) & Supplier integration $\&$ Turan, 2016a; Kim \& Kang, 2008) \\
(5) & Knowledge-based engineering, & (Echtelt \& Wynstra, 2001; Petersen, Handfield, \& Ragatz, \\
(6) & Modularity & (Khan \& Al-Ashaab, 2013; Stenholm, et al., 2015) \\
(7) & Visual management & (Carulli, Bordegoni, \& Cugini, 2013; Jurado, 2012; Parry \\
\hline
\end{tabular}

Following the algorithm in Section 3.2, in Step 1; the degree of the importance of each criterion (lean practice) from the expert's ratings are aggregated using the OWG operator to form the expert's comprehensive values. The result of the experts' ratings and their corresponding aggregation is shown in Table 4. In step 3, the expert's comprehensive values are inputted into the evaluation matrix and the computational result is shown in Table 5.

\section{Table 4}

Performance survey results for the relative importance of the lean practices

\begin{tabular}{ccccccccccccccc}
\hline & \multicolumn{4}{c}{ Top Management } & \multicolumn{4}{c}{ Design Engineers } & \multicolumn{3}{c}{ Research \& Development } & \multicolumn{3}{c}{ Sales/OEM customers } \\
\multirow{2}{*}{ OWG Operator } \\
\hline $\mathrm{A}_{\mathrm{i}}$ & E1 & E2 & E3 & E1 & E2 & E3 & E1 & E2 & E3 & E1 & E2 & E3 & $D_{i} W$ \\
\hline $\mathrm{A}_{1}$ & $(0.55$ & 0.55 & 0.30 & 0.15 & 0.45 & 0.50 & 0.20 & 0.25 & 0.25 & 0.30 & 0.30 & $0.30)$ & $(0.01102)$ \\
$\mathrm{A}_{2}$ & $(0.30$ & 0.10 & 0.15 & 0.10 & 0.25 & 0.20 & 0.20 & 0.10 & 0.10 & 0.15 & 0.15 & $0.10)$ & $(0.00043)$ \\
$\mathrm{A}_{3}$ & $(0.25$ & 0.15 & 0.35 & 0.15 & 0.45 & 0.30 & 0.45 & 0.45 & 0.15 & 0.35 & 0.25 & $0.15)$ & $(0.00455)$ \\
$\mathrm{A}_{4}$ & $(0.53$ & 0.25 & 0.45 & 0.35 & 0.45 & 0.15 & 0.15 & 0.20 & 0.35 & 0.45 & 0.20 & $0.35)$ & $(0.00747)$ \\
$\mathrm{A}_{5}$ & $(0.15$ & 0.15 & 0.35 & 0.10 & 0.20 & 0.15 & 0.10 & 0.20 & 0.25 & 0.10 & 0.15 & $0.10)$ & $(0.00068)$ \\
$\mathrm{A}_{6}$ & $(0.10$ & 0.15 & 0.25 & 0.15 & 0.25 & 0.30 & 0.15 & 0.45 & 0.15 & 0.25 & 0.10 & $0.15)$ & $(0.00130)$ \\
$\mathrm{A}_{7}$ & $(0.15$ & 0.25 & 0.10 & 0.25 & 0.10 & 0.20 & 0.20 & 0.35 & 0.25 & 0.10 & 0.15 & $0.25)$ & $(0.00114)$ \\
\hline
\end{tabular}


Table 5

Evaluation matrix and computational result for the lean practices

\begin{tabular}{cccccccc}
\hline $\mathrm{A}_{\mathrm{i}}$ & $\mathrm{A}_{1}$ & $\mathrm{~A}_{2}$ & $\mathrm{~A}_{3}$ & $\mathrm{~A}_{4}$ & $\mathrm{~A}_{5}$ & $\mathrm{~A}_{6}$ & $\mathrm{~A}_{7}$ \\
\hline $\mathrm{A}_{1}$ & 0.500 & 0.688 & 0.544 & 0.515 & 0.672 & 0.626 & 0.634 \\
$\mathrm{~A}_{2}$ & 0.312 & 0.500 & 0.350 & 0.325 & 0.481 & 0.431 & 0.440 \\
$\mathrm{~A}_{3}$ & 0.456 & 0.650 & 0.500 & 0.471 & 0.632 & 0.584 & 0.593 \\
$\mathrm{~A}_{4}$ & 0.485 & 0.675 & 0.529 & 0.500 & 0.658 & 0.611 & 0.620 \\
$\mathrm{~A}_{5}$ & 0.328 & 0.519 & 0.368 & 0.342 & 0.500 & 0.450 & 0.459 \\
$\mathrm{~A}_{6}$ & 0.374 & 0.569 & 0.416 & 0.389 & 0.550 & 0.500 & 0.509 \\
$\mathrm{~A}_{7}$ & 0.366 & 0.560 & 0.407 & 0.380 & 0.541 & 0.491 & 0.500 \\
\hline
\end{tabular}

The next step starts with the computation of the arithmetic mean matrix for the weight associated with the lean practices using the modified arithmetic mean weight Eq. (10). Details of the computation are given below, while the final computational result for the modified arithmetic mean weight equation is given Table 6.

Calculation of the Arithmetic mean for the weight of the lean practices;

$W_{A_{i}}=\frac{1}{E}\left[\sum_{j=1}^{E} \frac{D_{j} W}{D_{j} W+D_{j} W}\right]$

$W_{A_{1}}=\frac{1}{12}[0.500+0.688+0.544+0.515+0.672+0.626+0.634]=(0.348)$

Similarly, the Arithmetic mean for the other lean practices

Table 6

Arithmetic mean for the lean practice

\begin{tabular}{lc}
\hline$W_{A_{i}}$ & Arithmetic mean \\
\hline$W_{A_{1}}$ & 0.348 \\
$W_{A_{2}}$ & 0.237 \\
$\boldsymbol{W}_{A_{3}}$ & 0.324 \\
$\boldsymbol{W}_{A_{4}}$ & 0.340 \\
$\boldsymbol{W}_{A_{5}}$ & 0.247 \\
$\boldsymbol{W}_{A_{6}}$ & 0.276 \\
$\boldsymbol{W}_{A_{7}}$ & 0.270 \\
\hline
\end{tabular}

Finally, the priority weight for each of the lean practice is calculated using the Eq. (11). Details of the computation are given below, while the final computational result for the final fuzzy priority weight is given Table 7.

$$
\begin{gathered}
W_{F_{i}}=\left[\frac{W_{A_{i}}}{\sum W_{A_{i}}}\right] \\
W_{F_{1}}=\left[\frac{(0.348)}{(0.348+0.237+0.324+0.340+0.247+0.276+0.270)}\right] \\
=0.171
\end{gathered}
$$

Similarly, the Priority weight for the other lean practices is calculated, 
Table 7

Priority weight for the lean practice

\begin{tabular}{lcc}
\hline$W_{A_{i}}$ & Priority weight & Ranking \\
\hline$W_{F_{1}}$ & 0.171 & 1 \\
$W_{F_{2}}$ & 0.116 & 7 \\
$W_{F_{3}}$ & 0.159 & 3 \\
$W_{F_{4}}$ & 0.167 & 2 \\
$W_{F_{5}}$ & 0.121 & 6 \\
$W_{F_{6}}$ & 0.135 & 4 \\
$W_{F_{7}}$ & 0.132 & 5 \\
\hline
\end{tabular}

\subsection{Comparison and discussion}

To further demonstrate the effectiveness of the proposed subjective and objective fuzzy AHP model for the determination and prioritization of lean practices in a product development environment, we have compare the results of the above case study using some similar computational approaches including the Fuzzy Delphi Method proposed in (Ho \& Wang, 2008), and the fuzzy AHP model proposed in (Kong \& Liu 2005). The final ranking results for the different approaches have been presented in Table 8. The rankings show that the different computational approaches are almost in agreement with our proposed approach. Hence, the study can conclude that the model is effective, feasible and rational.

Table 8

Comparison of the extended fuzzy AHP and the traditional Fuzzy AHP

\begin{tabular}{lcccccc}
\hline $\mathbf{A}_{\mathbf{i}}$ & $\begin{array}{c}\text { Proposed } \\
\text { Model }\end{array}$ & Ranking & $\begin{array}{c}\text { (Ho \& Wang, } \\
\mathbf{2 0 0 8}\end{array}$ & Ranking & $\begin{array}{c}\text { Kong \& Liu } \\
\mathbf{2 0 0 5}\end{array}$ & Ranking \\
\hline $\mathbf{A}_{\mathbf{1}}$ & 0.171 & 1 & 0.343 & 1 & 0.090 & 1 \\
$\mathbf{A}_{\mathbf{2}}$ & 0.116 & 7 & 0.155 & 7 & 0.041 & 7 \\
$\mathbf{A}_{\mathbf{3}}$ & 0.159 & 3 & 0.288 & 3 & 0.075 & 3 \\
$\mathbf{A}_{\mathbf{4}}$ & 0.167 & 2 & 0.323 & 2 & 0.084 & 2 \\
$\mathbf{A}_{\mathbf{5}}$ & 0.121 & 6 & 0.168 & 6 & 0.044 & 6 \\
$\mathbf{A}_{6}$ & 0.135 & 4 & 0.205 & 4 & 0.054 & 4 \\
$\mathbf{A}_{\mathbf{7}}$ & 0.132 & 5 & 0.198 & 5 & 0.052 & 5 \\
\hline
\end{tabular}

\section{Conclusion}

In this paper, we have proposed a subjective and objective fuzzy AHP based model for the determination and prioritization of lean practices in a product development environment. In extending the fuzzy AHP model, a new evaluation matrix was developed to replace the traditional FCM, that have been found to be ineffective and time-consuming due to the repetitive adjustment of data when more criteria or alternatives are considered. The model which is based on a subjective and objective factors/approach can be said to have the following advantages;

(1) Using the subjective and objective fuzzy AHP based model can help in reducing the complete dependency on human judgment, and since the weights are solved automatically using the evaluation matrix and the modified priority weight formula.

(2) The experience and expertise of the assessors (experts) are considered and accounted for in the model; thereby striking a balance in the data collected and the prevention of expert's bias which could normally cause a sharp reduction in data inconsistency. 
(3) The data collected are based on membership scale, meaning the experts are allowed to have a partial agreement to a response or question and they can choose the answers from a range of data (interval),

(4) The proposed model is flexible, easy and the computation process is straightforward as compared to the other reviewed methods and finally.

(5) The objective aspect of determining the weight automatically using the mathematical model makes the result more reliable.

In demonstrating the effectiveness of the model, the subjective and objective fuzzy-based AHP model has been compared with some similar computational approaches including the Fuzzy Delphi Method proposed in (Ho \& Wang, 2008), and the fuzzy AHP model proposed in (Kong \& Liu 2005). The result from the case study and analysis shows that, set-based concurrent engineering has the highest priority weight of 0.171 , follow by Supplier integration and Cross-functional teams etc. the ranking order of the lean practices as determined are based on their ability to maximize product value, product quality as well as minimize product development time and cost.

Finally, we believe the understanding of the implementation priority of the lean practices from this study will serve as an advisory system and method for product development and manufacturing companies planning to evaluate their current practices and in the allocation of reasonable resources and efforts to maximize their product value, product quality as well as minimize their product development time and cost. In the future, the proposed model will be applied in other areas of industrial engineering.

\section{References}

Aikhuele, D. O., \& Turan, F. M. (2016a). A Hybrid Fuzzy Model for Lean Product Development Performance Measurement. IOP Conference Series: Materials Science and Engineering, 114(1), 012048. http://doi.org/10.1088/1757-899X/114/1/012048

Aikhuele, D. O., \& Turan, F. M. (2016b). Proposal for a Conceptual Model for Evaluating Lean Product Development Performance: A Study of LPD Enablers in Manufacturing Companies. 2Nd International Manufacturing Engineering Conference and 3Rd Asia-Pacific Conference on Manufacturing Systems (Imec-Apcoms 2015), 114. http://doi.org/10.1088/1757-899X/114/1/012047

Al-ashaab, A., Andino, A., \& Summers, M. (2013). Lean product development performance measurement tool. Proceedings of the 11th International Conference on Manufacturing Research (ICMR2013) Advances in Manufacturing Technology XXVII: 19-20 September 2013. Cranfield, Bedfordshire, UK., (September), 19-20.

Al-Ashaab, A., Golob, M., Urrutia, U. A., Gourdin, M., Petritsch, C., Summers, M., \& El-Nounu, A. (2015). Development and application of lean product development performance measurement tool. International Journal of Computer Integrated Manufacturing, (October), 1-13. http://doi.org/10.1080/0951192X.2015.1066858

Aly, S., \& Vrana, I. (2008). Evaluating the knowledge, relevance, and experience of expert decision makers utilizing the Fuzzy-AHP. Agricultural Economics, 54(11), 529-535.

Avicnnasis. (2011). Famous Theorems of Mathematics/Algebra/Matrix Theory.

Baruah, H., \& K. (1999). Set Superimposition and Its Application to the Theory of Fuzzy Sets. Journal of Assam Science Society, 40, 25 -31.

Braglia1, M., Frosolini, M., \& Montanari, R. (2003). Fuzzy TOPSIS approach for failure mode, effects, and criticality analysis. Quality and Reliability Engineering International, 19(5), 425-443.

Carulli, M., Bordegoni, M., \& Cugini, U. (2013). An approach for capturing the Voice of the Customer based on Virtual Prototyping. Journal of Intelligent Manufacturing, 24, 887-903. http://doi.org/10.1007/s10845-012-0662-5

Chaghooshi, A. J., Fathi, M. R., \& Kashef, M. (2012). Integration of fuzzy Shannon's entropy with 
fuzzy TOPSIS for industrial robotic system selection. Journal of Industrial Engineering and Management, 5(1), 102-114. http://doi.org/10.3926/jiem.397

Chang, D.-Y. (1996). Applications of the extent analysis method on fuzzy AHP. European Journal of Operational Research, 95(95), 649-655. http://doi.org/10.1016/0377-2217(95)00300-2

Chen, S.-M., \& Tan, J.-M. (1994). Handling multicriteria fuzzy decision-making problems based on vague set theory. Fuzzy Sets and Systems, 67(2), 163-172.

Chiclana, F., Herrera, F., \& Herrera-Viedma, E. (2002). The Ordered Weighted Geometric Operator: Properties and Application in MCDM Problems. In S. V. 90 (Ed.), Technologies for Constructing Intelligent Systems 2 (pp. 173-183). Physica-Verlag HD. http://doi.org/10.1007/978-3-7908-1796$6 \_14$

Christopher, T., \& John, J. S. (2014). Multicriteria decision technique on product prioritization. International Journal of Emerging Engineering Research and Technology, 2(3), 194-200.

Corallo, A., Laubacher, R., Margherita, A., \& Turrisi, G. (2009). Enhancing product development through knowledge-based engineering (KBE): A case study in the aerospace industry. Journal of Manufacturing Technology Management, 20, 1070-1083. http://doi.org/10.1108/17410380910997218

Daniel Osezua Aikhuele, Fathi S. Souleman, A. A. (2014). Application of Fuzzy AHP for Ranking Critical Success Factors for the Successful Implementation of Lean Production Technique. Australian Journal of Basic and Applied Sciences, 8(December), 399-407.

Echtelt, F. Van, \& Wynstra, F. (2001). Managing supplier integration into product development: a literature review and conceptual model. The Future of Innovation Studies, 1-22. Retrieved from http://cms.tm.tue.nl/Ecis/Files/papers/wp2002/eciswp55.pdf

GINEVIČIUS, R. (2011). A new determining method for the criteria weights in multi-criteria evaluation. International Journal of Information Technology \& Decision Making, 10(6).

Harland, P. E., \& Uddin, Z. (2014). Effects of product platform development: fostering lean product development and production. International Journal of Product Development, 19(5), 259-285. http://doi.org/10.1504/IJPD.2014.064881

Ho, Y., \& Wang, H. (2008). Applying fuzzy Delphi method to select the variables of a sustainable urban system dynamics model. ... Conference of the System Dynamics ..., 1-21. Retrieved from http://www.systemsmodelbook.org/uploadedfile/1376_272c89b6-32c7-4a9d-8a77b7c613d7a0d2 HO311.pdf

Hwang C. L., \& Yoon K. (1981). Multiple Attribute Decision Making Methods and Applications. Berlin: Springer.

Ishikawa, A., Amagasa, M., Shiga, T., Tomizawa, G., Tatsuta, R., \& Mieno, H. (1993). The max-min Delphi method and fuzzy Delphi method via fuzzy integration. Fuzzy Sets and Systems, 55(3), 241253. Retrieved from http://leansi.wp.mines-telecom.fr/files/2009/11/Oobeya-article-2009.pdf

Jurado, M. C. (2012). Visual Planning in Lean Product Development. Master Thesis.

Kahraman, C., Cebeci, U., \& Ruan, D. (2004). Multi-attribute comparison of catering service companies using fuzzy AHP: The case of Turkey. International Journal of Production Economics, 87(2), 171-184. http://doi.org/10.1016/S0925-5273(03)00099-9

Kao, C. (2010). Weight determination for consistently ranking alternatives in multiple criteria decision analysis. Applied Mathematical Modelling, 34(7), 1779-1787. http://doi.org/10.1016/j.apm.2009.09.022

Khan, M., \& Al-Ashaab, A. (2013). Towards lean product and process development. International Journal of Computer Integrated Manufacturing, 26(12), 1105-1116. Retrieved from http://www.tandfonline.com/doi/abs/10.1080/0951192X.2011.608723

Kim, B. Y., \& Kang, B. K. (2008). Cross-functional cooperation with design teams in new product development. International Journal of Design, 2(3), 43-54.

Kong, F., \& Liu, H. (2005). Applying fuzzy analytic hierarchy process to evaluate success factors of ecommerce. International Journal of Information and Systems Sciences, 1(3), 406-412.

Leonardi, G. (2016). A Fuzzy Model for a Railway-Planning Problem. Applied Mathematical Sciences, 10(27), 1333-1342. 
Li, C. Q. (2010). A New Likert Scale Based on Fuzzy Sets Theory. Ph.D. Thesis.

Ma, J., Fan, Z.-P., \& Huang, L.-H. (1999). A subjective and objective integrated approach to determine attribute weights. European Journal of Operational Research, 112(2), 397-404. http://doi.org/10.1016/S0377-2217(98)00141-6

Nurnadiah, Z., \& Lazim, A. (2012). A New Weight of Interval Type-2 Fuzzy Rasch Model. Applied Mathematical Sciences, 6(75), 3705-3722.

Oguztimur, S. (2011). Why Fuzzy Analytic Hierarchy Process Approach for Transport Problems? In European Regional Science Association ERSA Conference Papers, Augasse 2-6, 1090 Vienna, Austria, ersa1 1, 438. (pp. 1-19). Retrieved from http://www.screawu.ac

Parmar, K. R., \& Bhoi, U. (2015). Geometric Mean based Algorithm for Prioritizing Processors on Cloud Environment. International Journal of Computer Applications, 120(23), 14-18.

Parry, G. C., \& Turner, C. E. (2006). Application of lean visual process management tools. Production Planning \& Control, 17(1), 77-86. http://doi.org/10.1080/09537280500414991

Petersen, K. J., Handfield, R. B., \& Ragatz, G. L. (2003). A model of supplier integration into new product development. Journal of Product Innovation Management, 20, 284-299. http://doi.org/10.1111/1540-5885.00028

Petersen, K. J., Handfield, R. B., \& Ragatz, G. L. (2005). Supplier integration into new product development: Coordinating product, process, and supply chain design. Journal of Operations Management, 23, 371-388. http://doi.org/10.1016/j.jom.2004.07.009

Prasolov, V. (1994). Problems and Theorems in Linear Algebra. Americal Mathematical Society.

Pugh, S. (1996). Creating innovative products using total design: The living legacy of Stuart Pugh. Reading, MA: Addison-Wesley.

Ramik, J. (2009). Consistency of pair-wise comparison matrix with fuzzy elements. In Proceedings of the Joint 2009 International Fuzzy Systems Association World Congress and 2009 European Society of Fuzzy Logic and Technology Conference, Lisbon, Portugal, July 20-24, 2009. (pp. 98-101).

Roszkowska, E. (2013). Rank ordering criteria weighting methods - a comparative overview. Optimum.Studia Ekonomiczne Nr, 5(65), 14 - 33. http://doi.org/10.15290/ose.2013.05.65.02

Saaty, T. L. (2008). Decision making with the analytic hierarchy process. International Journal of Services Sciences, 1(1), 83. http://doi.org/10.1504/IJSSCI.2008.017590

Stenholm, D., Mathiesen, H., \& Bergsjo, D. (2015). Knowledge-Based Development in Automotive Industry Guided by Lean Enablers for System Engineering. Procedia Computer Science, 44, 244 253. http://doi.org/10.1016/j.procs.2015.03.047

Stirn, L. Z., \& Grošelj, P. (2010). Multiple Criteria Methods With Focus on Analytical Hierarchy Process and Group Decision-making. Croatian Operational Research Review, 1, 2-11.

Turan, F. B. M. (2013). A three-stage methodology for design evaluation in product development. Ph.D. Thesis, (December).

van Til, J., Groothuis-Oudshoorn, C., Lieferink, M., Dolan, J., \& Goetghebeur, M. (2014). Does technique matter; a pilot study exploring weighting techniques for a multi-criteria decision support framework. Cost Effectiveness and Resource Allocation: C/E, 12(1), 22. http://doi.org/10.1186/1478-7547-12-22

Verhagen, W. J. C., Bermell-Garcia, P., Van Dijk, R. E. C., \& Curran, R. (2012). A critical review of Knowledge-Based Engineering: An identification of research challenges. Advanced Engineering Informatics, 26(1), 5-15. http://doi.org/10.1016/j.aei.2011.06.004

Wang, Y. M., \& Chin, K. S. (2011). Fuzzy analytic hierarchy process: A logarithmic fuzzy preference programming methodology. International Journal of Approximate Reasoning, 52(4), 541-553. http://doi.org/10.1016/j.ijar.2010.12.004

Wu, W., Chiang, C., \& Lin, C. (1998). Comparing the aggregation methods in the analytic hierarchy process when uniform distribution. WSEAS Transactions on Business and Economics, 5, 82-87. 
C 2017 by the authors; licensee Growing Science, Canada. This is an open access article distributed under the terms and conditions of the Creative Commons Attribution (CC-BY) license (http://creativecommons.org/licenses/by/4.0/). 